\title{
Narrativas e políticas de um sertão e suas vidas severinas
}

\author{
Lázaro Batista da Fonseca \\ Universidade Federal de Roraima, Boa Vista, RR, Brasil
}

\begin{abstract}
Resumo
Como no histórico poema de João Cabral de Melo Neto, ainda hoje muitos severinos - maridos, pais, filhos e irmãos - saem do Nordeste brasileiro, motivados pelo sonho de prosperar na labuta e encontrar um sentido para suas existências, fugindo de um lugar de morte e indo em busca de outra vida. Considerando esses fluxos migratórios em sua forma sazonal, o presente texto é fruto de dissertação de mestrado que buscou problematizar os encontros dos moradores do semiárido do estado de Sergipe com as novidades e vicissitudes que o trabalho desses homens lhes propiciou e as alterações que produziu na vida do lugar e das pessoas. Para tanto, são apresentados fragmentos narrativos que buscam ilustrar alguns aspectos do cotidiano e dos processos sócio-históricos experimentados no lugar e pelas pessoas que nele moram ou moraram. Ademais, e especialmente, destaca-se a importância das mulheres severinas, que na sua potente capacidade de reinventar a vida em meio às adversidades, alargaram sua rede de sociabilidade.

Palavras-chave: migração; nordeste brasileiro; vida severina.
\end{abstract}

\section{Narrativies and policies of a wildness and their severinas lives}

\begin{abstract}
As the historical text by João Cabral de Melo Neto, even today many severinos - husbands, fathers, sons and brothers - leave the Northeast, motivated by dreams of thriving in toil and find a meaning for their existence, fleeing from a place that feels like death and going in search of another life. This work aims to discuss the meetings of inhabitants of a village in the semi-arid region of Sergipe state with news and vicissitudes that the work of these men gives them and the changes it produces in the life of the place and people. To this end, narrative fragments are presented that demonstrate some aspects of the daily life and socio-historical processes of the village and the people who live or lived there. In addition, and especially highlights the importance of women, severinas, who in their powerful ability to reinvent their lives in the midst of adversity that migration establishes, it also benefits by extending its network of sociability. Keywords: migration; Brazilian Northeast; severe life.
\end{abstract}

\section{Introdução: fragmentos de vidas severinas ${ }^{1}$}

Mulheres reunidas conversam efusivamente, enquanto desencascam lascas brancas de cocos. Uma negra alta, emperiquitada com bijuterias e um esmalte vermelho sobressaliente comanda o fazer. A voz grave e o corpanzil avantajado parecem conceder autoridade, embora não lhe subtraia certa graça que possui. Tem uma admirável destreza em enfiar a lâmina pontiaguda por entre a parte dura e a carne alva, sem deixar que o fruto se rompa, ou que o corte lhe fuja ao controle. Mais uma banda que sai inteira é jogada na velha bacia de alumínio, estrategicamente colocada no meio do círculo de mulheres. Eram todas moradoras da redondeza, tinham vindo ajudar as duas funcionárias, a negra de esmalte vermelho e uma senhora, ambas responsáveis pela rotina de afazeres daquele lugar. Sabiam, as duas e as que vieram ajudar, que o trabalho não era pouco.

Aquilo havia começado desde muito cedo do dia e já rompia a tarde. Primeiro foi necessário faxinar o prédio. Era dia de festa e a ocasião pedia que o lugar estivesse impecável. O salão, a recepção, as duas salas de atendimento, o velho laboratório empilhado de computadores sem uso... Tudo cheirava ao pinho barato, vendido de porta em porta. A negra alta, sem aparentar se importar muito se seu esmalte resistiria àquilo, limpava tudo com considerável rapidez. A quem credita pressa e perfeição como coisas que não podem andar juntas, ela parecia desdizer a crença alheia e o

\footnotetext{
^Endereço para correspondência: Universidade Federal de Roraima. Av. Cap. Enê Garcez, 2413. Aeroporto - Boa Vista, RR - Brasil. CEP: 69310-000. E-mail: lazaro.batista@ufrr.br

Os dados completos do autor encontram-se ao final do artigo.

${ }^{1}$ A narrativa contida neste fragmento foi extraída integralmente da dissertação de mestrado do autor (cf. FONSECA, 2013).
}

ditado popular. E isso enquanto cantarolava um ou outro verso de bregas e boleros antigos, assoviando os solos das canções que embalavam seu afazer com a mesma disposição que limpava o chão de cimento queimado.

Mas não se destacava apenas pelo talento em assoviar ou pela destreza no descascar cocos. Tinha a virtude e o defeito de despertar afeição nas pessoas. Certamente, muito mais pela sinceridade do que pela habilidade como cantora. Era de pouquíssimas palavras, mas elas bastavam. Era suficiente olhar para aquela negra Severina e perceber em suas expressões quando algo não lhe agradava. Não é que fosse de birras ou de fazer mau gosto nas coisas, apenas sabia impor-se, sabia se fazer entendida, mesmo que isso lhe custasse um tanto de desagravos. E não via nisso problema, antes preferia a cara de malgrado nos outros por dizer o que pensava do que se pôr como falsa ou dissimulada.

Se isso por vezes lhe causada desentendimentos, a eles respondia ciente de que nem sempre a afirmação da vida se dá pelo alinhavar perfeito das relações. Sabia ela que o desentendimento não é o conflito entre aquele que diz branco e aquele que diz preto. É o conflito entre aquele que diz branco e aquele que diz branco, mas não entende a mesma coisa ou não entende de modo nenhum que o outro diz a mesma coisa com o nome de brancura. E entre isso de branco e preto, sabia a negra Severina existirem infindáveis tons de cinza, de maneira que a afirmação de seus modos de fazer só lhe era possível expondo aos demais aquilo que achava e pensava, sem muitas tratativas diplomáticas ou meio termos. Melhor ser desentendida do que mal-entendida. Provocar a emergência do desdito às vezes é necessário. Ou 
melhor, é necessário. E de tanto desentender, esse seu modo de proceder por afrontamento era já um fazer político. Falava de uma política que não é firmada no consenso das falas, mas no desdizer entre elas, na quebra de supremacia entre um dizer e outro, na afirmação positiva dos opostos e dos antagônicos, para que daí apareça a melhor forma de compartilhar o mundo com outros.

Mas nem sempre foi assim. Foi essa mesma vida, que agora ela acreditava ser feita de atropelos e desentendimentos, que a ensinou a proceder do modo de agora. Severina por muito tempo cumpriu aquele que parecia ser o percurso das mulheres do lugar: casou-se muito jovem, parou de estudar quase nem tendo começado, teve uma penca de filhos, viveu de subsistência, torrou a pele negra no sol escaldante, migrou... Não que tenha feito isso tudo sem que se achasse algum lampejo de vida, mas eles eram sempre menores do que a voz dos que lhe diziam que aquilo não cabia no destino que lhe fora reservado. E isso durou até o dia em que o marido a trocou pela dependência na cachaça - vendida na bodega da esquina - e por uma meia dúzia de prazeres mundanos oferecidos noutros botecos, igualmente imundos e sedutores.

O homem saiu, mas não sem antes sovar mulher e filhos, sabe Deus com que motivação. Quanto a ela, com filho pequeno, barriga vazia e o sangue que corria no canto do lábio carnudo, não viu jeito, senão se arriscar nessa coisa de viver. O que restava aquela vida severina, senão pôr-se a lutar por permanecer viva?

Foi nessa mesma época e com essa viva necessidade que a sertaneja ouviu um alarmante grito que bradavam outros mortos-vivos sertão afora. A mulher identificou vozes exigindo garantia ou restituição de direitos. Direito a plantar, colher, produzir, viver. Severina reconheceu que aquelas vozes diziam coisas que ela gostaria também de dizer e pleitear. E do desespero fez-se novidade. E dela, fez-se Severina, a Sem-Terra.

Eram os idos anos 90. O sertão começava a experimentar iniciativas de ruptura com uma de suas marcas fundamentais: o latifúndio. Bem sabemos nós o papel que a criação de gado desempenhou na expansão territorial brasileira rumo ao interior, assim como é sabido que essa mesma expansão se deu à custa da centralização do poder econômico e político nas mãos dos chamados coronéis. Disso não precisamos falar muito. Novidade mesmo é o movimento de pressão instaurado por religiosos e populares, efetivado sob a bandeira vermelha do Movimento dos Trabalhadores Sem-Terra e que faz surgirem os primeiros assentamentos rurais em Sergipe. Severina Sem-Terra, desde o sempre pobre, sem marido há pouco tempo, de pouca instrução e alguns filhos pequenos ainda para criar, decidiu que já sendo sem muita coisa, não lhe custava quase nada apostar naquilo de reforma agrária. Foi à luta com a vida, aquele pouco que possuía. Fez-se acampada, tomou chuva e sol, derrubou mata e quase caiu morta em confronto. Até o dia em que mudou de alcunha: tornou-se Severina Assentada.

E assim descobriu que aquilo de apostar com a vida parecia ser um jeito razoável de viver mais, de se afirmar viva. Bem sabia que podia perder, mas, ainda aí, sairia ganhando algo. Tornou-se assentada, mas também desterritorializada. Não é que precisasse, como faziam muitos, negar absolutamente seu lugar. Muito pelo contrário, tornar-se 'legalmente dona' de um pedaço daquele chão apontou-lhe a necessidade e a possibilidade de inventar ali mesmo jeitos de fugir e resistir aos processos perversos do mundo. Sendo que 'a desterritorialização não pode significar o fim da localidade, mas sua transformação em um espaço', para Severina isso significou pôr em relevo sua história de sofrimento e agruras para, dessa mesma história, retirar elementos de resistência àquela vida que levava. Isso ao mesmo tempo em que buscava afirmar alguns outros componentes de positivação dessa mesma vida sofrida. Não se tratava, portanto, de negar aquela Severina que fora durante muito tempo, sertaneja infeliz, semianalfabeta, com filhos subnutridos, extremamente dependentes da cesta básica oferecida como favor político pela líder comunitária. Mas a essa(s) Severina(s) juntava-se agora outra, desejosa de ver-se ao menos parcialmente livre desses simulacros identitários, de refazer a cada dia a possibilidade de estar e permanecer viva, como os refrãos dos velhos boleros que assoviava.

Seguindo essa linha, decidiu que não bastava ter a terra, era preciso ter o que nela colocar ou plantar. Percebeu que muitos homens começavam a sair do povoado tentando juntar dinheiro lá fora. Ela não era homem, mas tinha alguns em casa. Foi assim que o filho mais velho, aquele por quem tinha maior apego, migrou para trabalhar como peão. Ao contrário de muitos que saíam porque entendiam ser a hora de se desgarrar mundo afora, foi a pedido da mãe. Só sua incumbência parecia semelhante à da maioria dos rapazes: iria, passaria algum tempo trabalhando, juntaria algum dinheiro - o suficiente para botar algumas cabeças de gado no terreno, ou para garantir algum sustento em períodos de safra fraca. Daí, retornaria. Novamente, uma aposta.

Mas não é que nisso de ser forte o filho aprendera direitinho com a mãe? Foi, ganhou dinheiro, mas não apenas isso. Os poucos anos de estudo e a habilidade de lidar com outros trabalhadores lhe deram alguma vantagem sobre os demais. Acabou se tornando encarregado. Não era mais apenas um peão, mas um peão que "subiu na vida", que alcançou sucesso, respeito e um alto salário. O dinheiro? Continuou mandando. Gado? Continuou a comprar. Mas o retorno tardava em se consumar e consumia a mãe. Nove anos de espera, precisamente. Quase uma década de distância, se é que se pode medir distância em anos ou saudade em metros. O filho não vê jeito, não tem tempo. Mesmo de avião, dizia que ficava difícil.

A mãe não se ressentia. Mas a saudade, esse revés de um parto, pede que, de vez em quando, lembrasse ao filho de que ainda esperava sua volta. Era só ele querer [...] (FONSECA, 2013, p. 79-82).

A narrativa acima busca ilustrar o objetivo do presente texto e aquilo que ele pretende problematizar. É apresentada a história de uma moradora do povoado de Santa Rosa do Ermírio, município de Poço Redondo, semiárido do estado de Sergipe. A história narrada remete a um contexto em que, para muitos filhos, netos e esposos da localidade, a sorte dos homens parecia estar ligada à fuga do povoado para trabalhar como "peão" da construção civil em diferentes regiões do país, visando ao acúmulo de algum capital e ao retorno - ou não - ao seu local de origem. 
Essa peregrinação de tantas vidas daquele lugar aponta para uma lógica perversa, mas ainda muito presente: a sorte, destino ou sina do desterro reservada aos homens, mas também a possibilidade de se pôr a caminho e descobrir a vida, o que ela é. Algo semelhante àquele Severino de João Cabral de Melo Neto (1987) que rumou em direção ao litoral, tentando ver beleza e encontrando sofrimento, até entender que isso é a vida, mesmo que sofrida. Sem desconsiderar tal discussão, a questão central que buscamos desdobrar com a história da Severina é: se Severino vai à cata da vida que ele acredita não encontrar em seu lugar - lugar de morte, o que restaria à(s) severina(s) que ali permanecem?

Desse modo, o presente texto tem o objetivo de problematizar as alterações nas vidas das pessoas e do lugar, suscitadas a partir da migração realizada por esses sertanejos, acenando para as formas de enfrentamentos a essa realidade que são engendradas. Em especial, recorre-se a essas mulheres severinas e seus encontros com as novidades e vicissitudes que essa modalidade de trabalho de seus homens lhes propicia. Para tanto, tenta-se captar como ocupam, se é que ocupam, aqueles territórios e que táticas desenvolvem para melhor se colocarem nele. Enfim, como se enxergam nesses lugares e como neles fixam territórios, entre a falta do ente, a expectativa por seu retorno e as exigências que sua ausência presentifica.

\section{Potências cotidianas do narrar}

É premente que comecemos por conceituar aquilo que estamos chamando "narrar". Uma primeira observação, ou afirmativa, é a possibilidade de contar histórias, de montar um mosaico escrito a partir de umas poucas vidas. Walter Benjamin (2012a), ao problematizar a função do narrador, afirma uma crise na atividade narrativa, em virtude da sobreposição da técnica sobre o homem. Segundo ele, essa sobreposição estabelece uma nova configuração na qual a arte de narrar estaria em vias de se extinguir, na medida em que cada vez mais se torna escassa a possibilidade humana de compartilhar experiências. A respeito disso, Benjamin identifica aquele que narra como alguém que dá conselhos, mas, afirma ele, dar conselhos é algo vazio de propósito aos homens da modernidade, já que estes não aspiram a novas experiências. Ao contrário, almejam "libertar-se de toda experiência, aspiram a um mundo em que possam ostentar tão pura e tão claramente sua pobreza externa e interna, que algo de decente possa resultar disso" (BENJAMIN, 2012b, p. 127).

Por outro lado, a perspectiva desse autor seria de afirmação da positividade do narrar, na medida em que, ao fazê-lo, atuamos em sentido contrário à pobreza das vivências individuais, em busca de uma ampliação da experiência compartilhada. Para tanto, Benjamin (2012a) abre mão de pensar o heroísmo ou gigantismo daquele que narra para positivar esse fazer como atrelado ao que há de mais banal ou ordinário nas nossas vidas, cidades e ruas (GAGNEBIN, 2004, 2009).

Nesse sentido, podemos pensar a narração como acontecimento forjado no cotidiano e a ele direcionado. A esse respeito, vale notar que Michel de Certeau (2007) ressalta o fato de que, tornando-se artimanha do fraco frente aos ditames que querem a vida despotencializada, uma prática tida como rotineira e cotidiana (e aqui estamos considerando o narrar como algo dessa ordem) tem a força de instaurar no bojo do discurso unívoco maneiras diferentes de se ver e fazer o mundo, as quais denotam uma resistência a esse discurso.

Essas “artes de fazer”, segundo ele, dão-se sub-repticiamente, nem sempre visíveis, mas sempre atuantes. Dada a sua aparente insignificância, passam por despercebidas ou pouco interessantes aos olhos do controle biopolítico da vida e, assim, logram destituí-lo. E, desse modo, contra a ideia de passividade ou docilidade, ressalta-se a ideia de astúcia, do "homem ordinário", que, apesar de anônimo, está a todo momento reinventando a si e ao mundo das formas as mais diversas. Ao mesmo tempo, tem-se a produção de uma vida cotidiana atenta para a singeleza, ali onde tudo o mais desconhece importância.

Como ilustram bem os personagens do filme nacional Narradores de Javé (2003), narrar torna-se, portanto, o ato de engrandecer as sutilezas desse ordinário. Não para pô-las como exemplo ou modelo, ou para evitar que as novidades as suplantem, mas para lhes dignificar o mero fato de serem. No caso do filme, para que as histórias continuem existindo apesar da inundação (NARRADORES..., 2003). Já para os propósitos deste texto, isso nos serve para propor e sustentar certa política de narratividade na escrita da vida cotidiana num meio rural que é jateado por novas vontades e ambições, ao mesmo tempo em que ainda se liga às suas tradições e costumes.

A migração feita pelos homens parece cumprir essa função: a de carregar a anunciação das novidades, de levar o novo ao povoado e, por outro lado, atualizar aquilo que de antigo ainda persiste nas vidas do lugar. E não estamos falando unicamente, ou especialmente, das mudanças econômicas, mas de novos modos de amar, viver, gozar, compartilhar, separar e partir. Por isso, ao invés de nos prendermos unicamente a análises e queixumes sobre uma tal crise de valores de nossa contemporaneidade, parece imprescindível também demarcar trincheiras de resistência à empreitada de ordenamento sumário da vida. Tal qual os poetas, artistas e mesmo historiadores que, na visão de Benjamin (2012a), ao juntar os rastros/ restos que sobejam da vida e da história oficial, ocupam a função do narrar.

\section{Um fazer-psicólogo e uma experiência feita campo}

Dentro desse circuito, este trabalho resulta de inquietações nutridas durante o período de atuação do autor como componente da equipe técnica de um Centro de Referência em Assistência Social do município de Poço Redondo, estado de Sergipe. As informações referem-se ao ano de 2013, durante o qual, três dias por semana, acompanhou famílias em situação de vulnerabilidade social, realizando visitas domiciliares e participando das atividades dos grupos de convivência.

Nesse contexto, o trabalho do psicólogo pode ser definido segundo algumas nuanças. Uma delas é aquela que encontra respaldo na necessidade de "garantia dos direi- 
tos", afirma a atuação do psicólogo e dos demais componentes do Centro de Referência como voltados a inserir socialmente pessoas em situação de vulnerabilidade social, de lhes permitir o acesso a serviços e possibilitar o convívio e a interação social. Uma outra nuança refere-se ao fato de essa atuação praticamente não se pautar pela escuta individual, fechada no consultório de atendimento, mas buscar compreender os arranjos sócio-históricos que compõem e interferem na vida daqueles que demandam o serviço, tentando, a partir daí, ajudá-los na compreensão e/ou alteração de sua realidade social. Uma clínica social, digamos, baseada na ideia de que a subjetividade não se funda num núcleo individual, mas é imanente a um campo social entrecortado por linhas de virtualidade, de situações, acontecimentos (ROMAGNOLI, 2006).

Um aglomerado de forças que emergem, configuram-se e reconfiguram-se nos encontros e relações que esse sujeito estabelece em sua vida (DELEUZE; PARNET, 1998). E, desse modo, expande-se o olhar para além dos consultórios, dos settings convencionais, estabelecendo outros olhares, conexões, redes. Conforme apontado pelo Centro de Referência Técnica em Psicologia e Políticas Públicas [CREPOP] (2007), um trabalho que se volta para a oportunidade de lidar com a vida, com a devolução da contradição para a sociedade, quando muitos se veem usurpado do usufruto da cidadania.

Por outro lado, também o psicólogo é convidado a se perguntar sobre o seu fazer, inquirindo-se a todo instante a respeito das decisões que toma, dos caminhos pelos quais opta e daquilo que põe fora de relação, quando o faz. Mas esse perguntar não é vertido necessariamente para a obtenção de resposta ou reafirmação de uma verdade. Embora não se negue a responder os questionamentos que lança, seu objetivo maior é produzir certa afetação que nos motive a outras e novas perguntas, inclusive abandonando vias já sedimentadas ou recorrendo a outros meios de inquirir-se. Por exemplo, fazendo de sua função um campo de estudo.

E é por essa opção que aquilo que era um ofício orientado pelos preceitos acima, acabou desdobrando-se em campo de pesquisa, conforme a mesma postura teórico-metodológica. O território e as famílias acompanhadas foram objeto de estudo ao longo do mestrado do autor em Psicologia Social, com a produção de diários de campo e entrevistas com moradores. Dessa maneira, foi possível ter acesso a muitas histórias do lugar e das pessoas que nele moram ou moraram, seja desempenhando a função técnica de psicólogo, seja em conversas formais e informais com moradores e usuários do serviço.

Temos, portanto, um duplo jogo de papeis e interesses. O primeiro deles, o da atuação de um profissional de psicologia, voltado ao atendimento das demandas e que, por elas, estabelece aproximação com a dinâmica do lugar e de suas gentes. Nesse nível, convive-se com as contradições e o limite estreito entre o poder institucional que o cargo sugere, as verdades que o sustentam e aquelas que nós mesmos sustentamos. O segundo movimento, concomitante ao primeiro, se afirmaria como tentativa de supressão ao menos parcial desse lugar institucional, ser- vindo-se como um processo de "estranhamento" (MAGNANI, 2009; CAIAFA, 2007) das ocupações e rotinas. Nele, saímos dos lugares instituídos de escuta e a eles retornamos, em busca de outros prismas e outros modos de problematizar as histórias. Mas o que elas nos contam?

\section{O que contam as vidas severinas?}

A localidade estudada se caracterizava por um sintomático quadro de pauperização social e econômica, com forte presença de programas assistenciais de transferência de renda e resquícios de ações ainda paternalistas e coronelistas. Nesse cenário, a possibilidade de ir trabalhar, mesmo que longe, juntar algum dinheiro e retornar algum tempo depois aparecia como muito atrativa. Tanto que os homens acabavam abrindo mão das próprias famílias para fazê-lo.

Assim, havia no município um número considerável de homens, denominados "peões", que migravam frequentemente para trabalhar em "firmas" noutros estados. A história desses peões, por seu turno, guardava algumas particularidades. A primeira era que eles não se transferiam definitivamente de lugar. Iam de tempos em tempos para as tais firmas - algo em torno de 6 a 12 meses, retornando depois para sua terra de origem. Ou seja, faziam o que se define como "migração sazonal": mesmo mantendo a posse de parcelas diminutas de terra, veem-se obrigados a se inserirem em atividades urbanas e/ou rurais, fora de seus locais de origem, reafirmando uma trajetória social acentuadamente voltada para a proletarização, seja ela permanente ou temporária (BOTELHO, 2003, p. 2).

Esse tipo de migração é recorrente em muitos municípios do Nordeste e já extensivamente estudada por pesquisadores. Os estudos comumente tratam da migração de trabalhadores para o interior dos estados de São Paulo, Rio de Janeiro e Minas Gerais, onde eles realizam a colheita de cana, café ou laranja e depois regressam para a terra natal. Mas, no caso da migração sazonal feita pelos poço-redondenses, o destino era outro: ao invés de se estabelecerem nos centros agroindustriais, estabeleciam-se durante um tempo em obras da construção civil no norte ou centro-oeste brasileiro e, após algum tempo, retornavam à localidade de origem (CORREIA; ALMEIDA, 2007). Muitas dessas construções eram financiadas pelo poder público e executadas por conglomerados da construção civil. Obras, poder público e construtoras estiveram presentes nos noticiários dos últimos cinco anos, relacionados a esquemas de corrupção, mas também relatando problemas, atrasos, greves, paralisações e mortes de operários.

A segunda particularidade era o fato de que a quase totalidade de trabalhadores eram homens; frequentemente, com pouca instrução. Alguns não possuíam nem sequer o dinheiro das passagens. Muitos deles fazendo sua primeira viagem para fora do povoado onde nasceu, sem muitas perspectivas de trabalho e vindos de famílias, do mesmo modo, pobres. E eram em grande quantidade. Embora não houvesse números oficiais, numa cidade com população estimada em 30 mil habitantes, falava-se algo em torno de quatro a sete mil poçorredondenses trabalhando como peões. 
Muitos deles enviavam remessas frequentes às famílias, e era desse dinheiro que provinha todo ou grande parte do sustento. Por outro lado, é de se crer que, para as firmas, a realidade vivida por esses homens também parecia torná-los muito atrativos como mão de obra. Eram pobres, nordestinos, com pouca instrução, aparentemente sem muitas perspectivas e, por isso - assim deveriam crer as firmas, em muito apoiadas no discurso midiático e no imaginário do Nordeste como terra devastada e de poucas possibilidades -, mais suscetíveis à docilização. Esfacelar as referências dos homens, fazendo-os voltar-se unicamente para a atividade produtiva, tornar-se-ia um jeito de garantir que agissem de acordo com essa ideologia (FOUCAULT, 1997).

Assim, a notória discrepância entre o número de mulheres e o de homens aparece atrelada a outras duas questões; a primeira diz respeito às circunstâncias que produzem a necessidade de migrar. Certos arranjos que extirpam (mesmo que temporariamente) esses sertanejos daquelas que eram suas ligações mais fortes: a família, a comunidade, a terra. Um extirpar que poderia parecer doloroso, mas que também se mostrava sedutor, pois vinha prenhe de possibilidade de alcançar outros meios de vida, diferentes daqueles que eles conheciam.

Bom, se tantos homens estavam fora, recaíam sobre as mulheres mais algumas responsabilidades e papeis. Essa era mais uma especificidade dali, ainda mais sendo aquele um lugar em que ainda parecia vigorar certo modo machista de conceber as relações e de estruturação social. A partir dos contatos, conversas e fragmentos narrativos inventariados ao longo de seis meses, pôde-se perceber que esse ranço ainda é extremamente forte na imagem patriarcal de família, na submissão das mulheres e filhos à figura do pai ou no papel subalterno que as mulheres exercem, de modo geral, diante dos homens. Pode ser pretensão afirmá-lo, mas cremos que aqui resida um dos motivos de saída de tantos homens para as firmas: é o preço que se paga por ser o homem. Ou seja, também sobre eles recaía esse machismo, obrigando-os a admitir seu papel de provedor do sustento e de "cabeça" da família.

Mas e as mulheres? Qual a parte que lhes cabe nessa conta? Se aos maridos, pais, filhos e irmãos era reservado o sonho ou obrigação de prosperar na labuta, às suas mulheres, o que era reservado? E o que delas se esperava? E o que elas esperavam: o marido, a separação, mais um filho, nada? Enfim, como sobreviviam à condição que a vida lhes impingia?

As respostas a essas questões apontam para dois aspectos. O primeiro deles: como as idas e vindas desses homens promoviam alterações na vida da comunidade $\mathrm{e}$ de seus moradores? Aqui falamos de uma série de mudanças econômicas e sociais, paulatinamente introduzidas no cotidiano da comunidade, graças aos encontros que seus homens estabeleceram, quando fisicamente ausentes de sua terra natal. Indicativos dessas mudanças são, por exemplo, a substituição dos animais por motocicletas nas lavouras, o aumento do número de acidentados em virtu-

de dessa substituição, a maior frequência no consumo de álcool e outras drogas, assim como os rearranjos familiares decorrentes de separações, ausências e reencontros.

Ou seja, a migração sazonal implicava adequações de projetos de vida ou das políticas que geriam essas adequações. Isso ocorria, por exemplo, em relação à necessidade de adequação das escolas a essa realidade, já que muitos adolescentes esperavam apenas completar 18 anos para abandonar os estudos e viajar para trabalhar. Havia implicações psicossociais também para muitas adolescentes, que, ainda frequentando as escolas e já casadas e com filhos, tinham que dividir o tempo entre as atividades escolares e o cuidado com a casa.

Conforme ilustra o texto de abertura e apontam outras narrativas inventariadas, por vezes resta às mulheres severinas o papel duplo e contraditório de estar sob o jugo de um homem nem sempre presente fisicamente e, ao mesmo tempo, ter que substituí-lo naquilo que a vida passa a lhes exigir depois da ida dos maridos, irmão e filhos para as firmas. Um claro exemplo disso era o destino dado à boa quantia de dinheiro enviado pelo "homem da casa". $\mathrm{Na}$ sua ausência, eram as mulheres quem investiam o montante na compra de algum animal, fazendo agiotagem ou guardando para "juntar". Ou seja, elas desempenhavam funções distintas daquela que uma sociedade patriarcal impõe como atribuições femininas na família. Por outro lado, essas decisões por vezes não passavam, senão com a anuência ou conhecimento do homem, reproduzindo a hierarquização social historicamente vista.

É importante deixar claro que essa anuência/conhecimento marca um modo de relação com a vida para as mulheres, mas não era exclusivo ou único. Pode-se mesmo dizer que essa relação não era sequer a essencial/ fundamental dessas existências. Assim sendo, o que se pretende demarcar como mais importante é certa afirmação positiva das severinas, seja no enfrentamento das mudanças inauguradas por esses novos tempos sertanejos, seja pelos modos como se posicionavam diante de aspectos sociais e históricos ainda reificados naquele peculiar rincão brasileiro.

Assim, para além da constatação de que na ausência dos homens essa severinas tornavam-se as principais responsáveis por gerir tudo, de dinheiro a afetos, pode-se, considerando não ser tão raro encontrar mulheres mães de família, contra-argumentar a respeito do que as fariam especiais. Como se tenta demonstrar na seção de abertura, não parecia haver nada de extraordinário nas suas vidas, a não ser a força com que a elas se agarravam. Aqui, vale mencionar Euclides da Cunha (1984), que, cobrindo jornalisticamente a Guerra de Canudos, em meados dos anos 1900, proferiu uma frase que se tornou a alcunha de referência do povo nordestino. Como um contador de história, Euclides estava lá para narrar. Aquilo que seus olhos viam por entre a terra vermelha, salpicada de sangue e suor de fiéis e soldados, porém, destoava um tanto daquilo que aparecia nos jornais da época e no ideário das pessoas. Daquela terra pobre e estéril, ele vislumbrava crescer o fruto de uma renitência: a força das pessoas. A pujança em resistir e insistir contra a seca, o cercado 
e a sede. E eis que sua frase se tornou famosa, tanto que não é preciso repeti-la aqui para que se saiba de qual trecho de Os sertões estamos falando.

É essa mesma potência inventiva, ou resistência (FOUCAULT, 2008), que as vidas severinas prenunciam. Mas a ela acrescentam outra, talvez incompreensível a Euclides: não apenas de força se faz uma guerra. Às vezes é necessário abrir mão de todo peso, agir na singeleza dos gestos: jeitos, artifícios, construções e ideias que atentam contra com um modus operandi único de ser severina, sertaneja, nordestina.

Assim, as narrativas inventariadas também nos contam como, em meio a tais processos de mudança, essas mulheres, jovens ou velhas, empregadas ou donas de casa, casadas ou solteiras, conviviam, conversavam e entrincheiravam-se nas singularidades de seu território; e como, nessa conjuntura completamente desfavorável, estabeleciam - muitas vezes como seus próprios corpos - tentativas de escape de uma "identidade" que as vinculasse a uma sina ou destino.

Como aquelas que ficam no lugar de morte, enquanto os homens vão à cata da vida, as vidas severinas acenam para modos de ser e estar no mundo que, a despeito do que querem e professam os discursos, inventam em sua existência ordinária e comum táticas de enfrentamento e resistência às suas mazelas (CERTEAU, 2007). No mais, servem também de indicativo daquele sertão como um lugar de invenções (ALBUQUERQUE JR., 1999). Um espaço "em vias de" (DELEUZE, 1992).

Por esse ângulo, suas histórias nos servem também para pensar a atualidade do sertão nordestino para além das representações habituais que se faz dele. Um sertão contemporâneo, não reconhecível apenas pela pobreza e miséria de sua gente, pela seca ferina, pelo atraso em relação às regiões economicamente desenvolvidas do país, como tem sido o usual e corriqueiro retrato que se faz da região. Apontam as vidas severinas para desdizer a região como um lugar de morte, mais do que de vida. Ao mesmo tempo, fazem supor a iminência doutros modos de se ver e viver (n)aquelas paragens.

Severinas de um sertão possuidor de uma história e que, por ela, não pode ser encerrado na regularidade de certos temas, falas e imagens que se afirmam e reafirmam na recorrência dos discursos (ALBUQUERQUE JR., 1999). Ou seja, se lugar de morte, como anunciava o Severino cabralino, também de vida, mesmo que radiculada ou dispersa numa profusão de falas e práticas reificadas.

Surge daí a necessidade de se pensar outras leituras e feituras do Nordeste, que absorvam essas comunicações silenciosas que se fazem vivas e pujantes no íntimo das relações e das pessoas. De forma que não se trate de buscar uma cultura nacional ou regional, uma identidade cultural ou nacional, mas de ressaltar as heterogeneidades que compõem e encerram cada um de nós, como pessoa e como povo. Enfim, anunciam as severinas a necessidade de buscarmos ser sempre diferentes, dos outros e em nós mesmos (FOUCAULT, 2012).
Um Nordeste, seu sertão e sua gente entendido não como um lugar cristalizado, fechado, mas como um território vivo. Nessa direção, o que se propõe é pensarmos o nordestino, seus severinos e severinas, não como vidas prontamente finalizadas, reservadas a um destino que lhes fora lançado antes mesmo que existissem como viventes. Para além da mera localização geográfica ou identidade, os quais os definem exclusivamente nos termos impressos, seja no papel, seja nas cabeças dos homens, pensar que é urgente e possível inventar outros meios de se viver e estar no mundo (KASTRUP, 2007).

Enfim, se o Severino ia em busca da vida, longe de onde parecia apenas achar a morte, para a Severina o enfrentamento da mortificação dava-se no embate corporal com seu tempo e lugar. Um tempo e lugar em que dialogam e digladiam-se vontades, verdades e discursos nem sempre explícitos, mas também onde se fecundam estratégias de escapamento a essas verdades e vontades. Estratégias muitas das vezes cooptadas, outras tantas percebidas apenas pelos rastros que deixam. Mas sempre indícios de vidas em transformação e mudança.

\section{Informações sobre 0 autor}

\section{Lázaro Batista da Fonseca \\ (iD http://orcid.org/0000-0002-3224-411X \\ (9) http://lattes.cnpq.br/2102030723410948}

Doutor em Psicologia (Estudos da Subjetividade) pelo Programa de Pós-graduação em Psicologia da Universidade Federal Fluminense, Mestre em Psicologia Social e Política pela Universidade Federal de Sergipe, especialista em Saúde Coletiva e Graduado em Psicologia (Formação de Psicólogo) pela Universidade Federal de Sergipe. Tem experiência no atendimento clínico-ambulatorial no Sistema Único de Saúde e como Psicólogo integrante de equipes técnicas em equipamentos públicos de Assistência Social. Integrante do GT "Políticas de Subjetivação e Invenção do Cotidiano" da ANPEPP. Professor Adjunto do Curso de Psicologia da Universidade Federal de Roraima e Docente do Programa de Pós-graduação em Comunicação da UFRR. Atua a partir de interlocuções entre Saúde Coletiva, Análise Institucional e Psicologia Social, centrando-se nas seguintes áreas de interesse e campos de problematização: psicologia social; saúde coletiva; fronteiras e limiares; políticas das imagens; experiência urbana; precariedade e processos de subjetivação contemporâneos.

\section{Como citar este artigo:}

\section{ABNT}

FONSECA, Lázaro Batista da. Narrativas e políticas de um sertão e suas vidas severinas. Fractal: Revista de Psicologia, Niterói, v. 32, n. 3., p. 246-252, set./out. 2020. https://doi.org/10.22409/19840292/v32i3/5686

\section{APA}

Fonseca, L. P. (2020, Setembro/Outubro). Narrativas e políticas de um sertão e suas vidas severinas. Fractal: Revista de Psicologia, 32(3.), 246-252. doi: https://doi.org/10.22409/1984-0292/ v32i3/5686 


\section{Copyright:}

Copyright (C) 2020 Fonseca, L. P. Este é um artigo em acesso aberto distribuído nos termos da Licença Creative Commons Atribuição que permite o uso irrestrito, a distribuição e reprodução em qualquer meio desde que o artigo original seja devidamente citado.

Copyright (C) 2020 Fonseca, L. P. This is an Open Access article distributed under the terms of the Creative Commons Attribution License, which permits unrestricted use, distribution, and reproduction in any medium, provided the original article is properly cited.

\section{Referências}

ALBUQUERQUE JR., Durval Muniz. A invenção do Nordeste e outras artes. São Paulo: Cortez, 1999.

BENJAMIN, Walter. O narrador: considerações sobre a obra de Nikolai Leskov. In: Magia e técnica, arte e política. Tradução de Sérgio Paulo Rouanet. 8. ed. São Paulo: Brasiliense, 2012a. v. 1, p. 213-240. Obras escolhidas.

BENJAMIN, Walter. Experiência e pobreza. In: Magia e técnica, arte e politica. Tradução de Sérgio Paulo Rouanet. 8. ed. São Paulo: Brasiliense, 2012b. v. 1, p. 123-128. Obras escolhidas.

BOTELHO, Maria Izabel Vieira. Experiências e vivências na migração sazonal. Unimontes Científica. Montes Claros, v. 5, n. 2, jul./dez, 2003. Disponível em: http://www.ruc.unimontes. br/index.php/unicientifica/article/view/157. Acesso em: 13 out. 2018.

CAIAFA, Janice. Aventuras das cidades: ensaios e etnografias. Rio de Janeiro: FVG, 2007.

CENTRO DE REFERÊNCIA TÉCNICA EM PSICOLOGIA E POLÍTICAS PÚBLICAS. Conselho Federal de Psicologia. Referências técnicas para atuação do (a) psicólogo (a) no CRAS/SUAS. Brasília: CFP, 2007.

CERTEAU, Michel de. A invenção do cotidiano. Petrópolis, RJ: Vozes, 2007.

CORREIA, Ben-Hur; ALMEIDA, Raquel. Povoado de Santa Rosa do Ermírio tem uma hora de água por semana. Infonet [online], 10 nov. 2007. Disponível em: https://web.archive.org/web/20071112070630/ http://www.infonet.com.br/politicaeeconomia/ler. asp?id=67401\&titulo=politicaeeconomia. Acesso em: 20 ago. 2020 .

CUNHA, Euclides da. Os sertões. São Paulo: Três, 1984.

DELEUZE, Gilles. Conversações. São Paulo: Ed. 34, 1992.

DELEUZE, Gilles; PARNET, Claire. Diálogos. São Paulo: Escuta, 1998.

FONSECA, Lázaro Batista da. Severinas missiveiras: narrativas sobre a invenção da vida num sertão contemporâneo. 2013. Dissertação (Mestrado em Psicologia Social) - Programa de Pós-graduação em Psicologia da Universidade Federal do Sergipe, São Cristóvão, 2013.

FOUCAULT, Michel. Vigiar e punir: história da violência nas prisões. Petrópolis, RJ: Vozes, 1997.

FOUCAULT, Michel. Microfisica do poder. Rio de Janeiro: Graal, 2008.
FOUCAULT, Michel. O que são as luzes? In: MOTTA, Manoel Barros da. (Org.). Arqueologia das ciências e história dos sistemas de pensamento. Rio de Janeiro: Forense Universitária, 2012. Coleção Ditos \& Escritos, v. 2, p. 351-368.

GAGNEBIN, Jeanne Marie. História e narração em Walter Benjamin. São Paulo: Perspectiva, 2004.

GAGNEBIN, Jeanne Marie. O rastro e a cicatriz: metáforas da memória. In: . Lembrar, escrever, esquecer. São Paulo: Ed. 4, 2009. p. $107-118$

KASTRUP, Virgínia. A invenção de si e do mundo: uma introdução do tempo e do coletivo no estudo da cognição. Rio de Janeiro: Autêntica, 2007.

MAGNANI, José Guilherme C. Etnografia como prática e experiência. Horizontes Antropológicos [online], ano 15, n. 32, p. 129-156, 2009. https://doi.org/10.1590/S010471832009000200006

MELO NETO, João Cabral de. Morte e Vida Severina. Rio de Janeiro: José Olympio, 1987.

NARRADORES de Javé. Direção: Eliane Caffé. Produção: Vânia Catani. Estúdio: Bananeira Filmes/Gullane Filmes/ Laterit Productions. Rio de Janeiro: Riofilme. 2003. 1 DVD (100 min).

ROMAGNOLI, Roberta. Algumas reflexões acerca da clínica social. Revista do Departamento de Psicologia - UFF [online], Niterói, v. 18, n. 2, p. 47-56, 2006. http://dx.doi.org/10.1590/ S0104-80232006000200004 